\title{
Thai psychiatrists and burnout: a national survey
}

\section{Neshda Nimmawitt ${ }^{1}$, Kamonporn Wannarit ${ }^{1}$, Pornjira Pariwatcharakul ${ }^{1}$}

${ }_{1}^{1}$ Department of Psychiatry, Faculty of Medicine Siriraj Hospital, Mahidol University, Bangkok, Thailand.

*Correspondence: nim.sunnyday.palm@gmail.com, kamonporn.wan@mahidol.edu, pornjira.par@mahidol.edu

\section{Background}

Thailand was among countries facing with increasing number of patients with mental illness, the number of Thai psychiatrists is still limited compared to the amount of workload. Accordingly, Thai psychiatrists are highly prone to burnout, and this could lead to many other mental health problems.

\section{Objective}

To explore the prevalence of burnout among Thai psychiatrists and to study the association of possible factors and burnout levels.

\section{Method}

In this cross-sectional study, online questionnaires were sent out to all registered Thai psychiatrists and residents. We focused on four domains, i.e. demographic data, burnout (measured with the Maslach Burnout Inventory ${ }^{1}$ ), coping mechanism (assessed with the Proactive Coping Inventory ${ }^{2}$ ), and strategies which Thai psychiatrists believed could help reduce their burnout.

\section{Result}

\section{Demographic data and work characteristics}

The response rate was $27 \% \quad(n=227)$. The majority of participants were female (70\%) and aged between 25-64 years (mean 36.84). Most of them were general psychiatrists (58.1\%), single (55.9\%) and had no children (72\%). The average number of years of experience as a psychiatrist was 8.9 years, while the mean number of patients per day was 28 . Their number of 'days off' per month was around 6-8 days.

Figure 1 Burnout rates by Maslach Burnout Inventory subscales

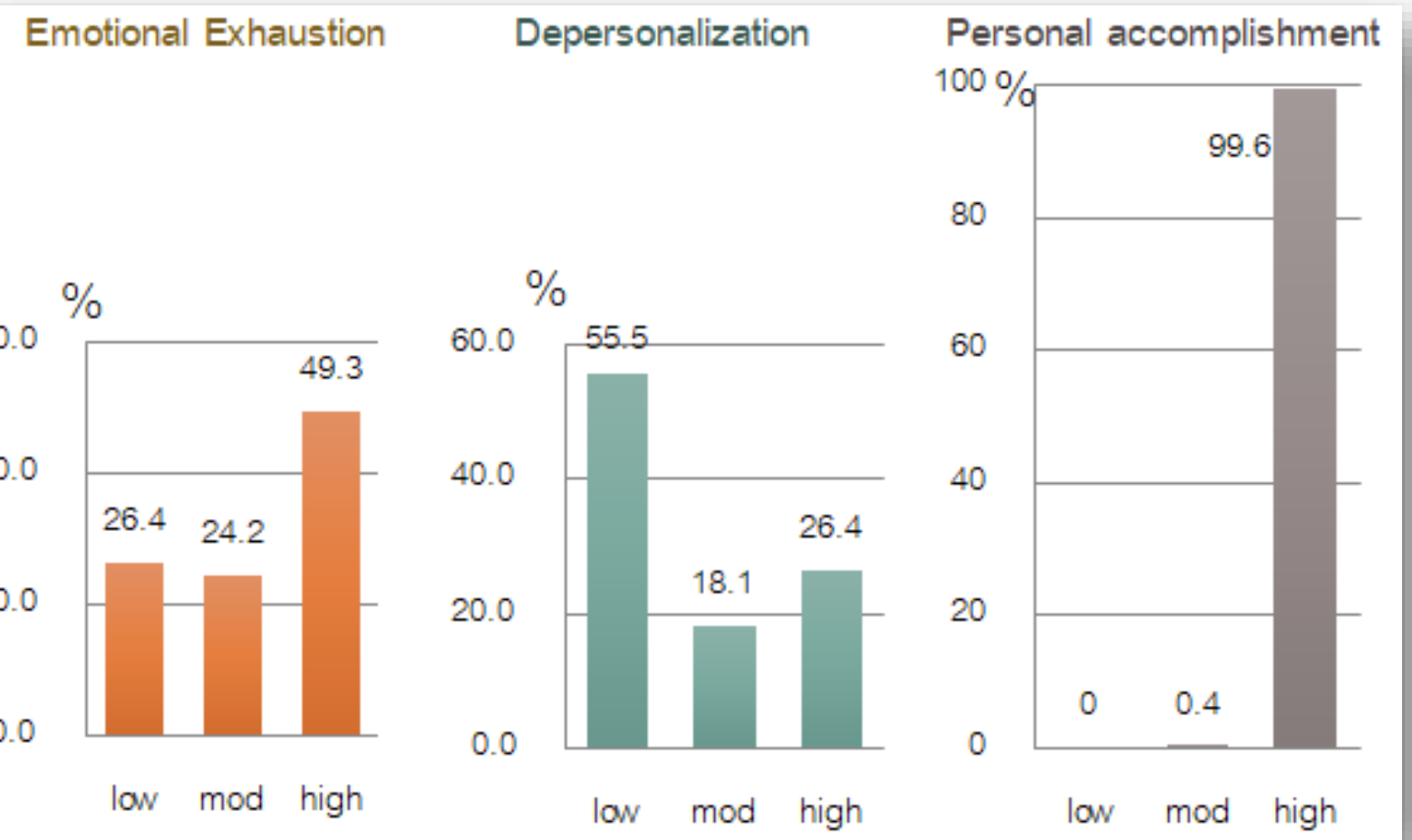

\section{Proactive coping mechanism and burnout}

There were significant correlations between each coping mechanism and burnout. Higher scores of proactive coping, strategic planning and emotional seeking were associated with less burnout ( $r=-0.165$ to -0.410$)$. On the other hand, higher avoidance coping scores were associated with more burnout $(r=0.169$ to 0.296$)$.

\section{Table1 Association between burnout and possible factors}

\begin{tabular}{|l|c|r|}
\hline Emotional exhaustion & B & P-value \\
\hline Working more than 50 hours per week & 2.958 & 0.003 \\
\hline Support from families & -3.263 & 0.041 \\
\hline Having satisfaction with work & -3.035 & $<0.001$ \\
\hline Emotional support seeking & -0.569 & 0.008 \\
\hline Depersonalization & B & P-value \\
\hline Avoidance coping & 0.634 & 0.005 \\
\hline Number of patients per day & 0.092 & $<0.001$ \\
\hline Having good support from colleagues & -1.468 & 0.033 \\
\hline Having more than one child & -1.301 & 0.018 \\
\hline Having satisfaction with work & -1.002 & $<0.001$ \\
\hline Proactive coping & -0.150 & 0.047 \\
\hline Personal accomplishment & B & P-value \\
\hline Having satisfaction with work & -1.092 & $<0.001$ \\
\hline Proactive coping & -0.275 & $<0.001$ \\
\hline
\end{tabular}

$\mathrm{B}=$ Unstandardized coefficients

\section{Conclusion}

Compared to a previous study on burnout among Thai psychiatrists in $2011^{3}$, the prevalence of high level of burnout increased dramatically. Adjusted the associated factors may be beneficial in relieving burnout.

References

1. Maslach C, Jackson SE. The measurement of experienced burnout. Journal of Organizational Behavior. 1981;2(2):99-113.

2. Greenglass, E., Schwarzer, R., Jakubiec, D., Fiksenbaum, L., \& Taubert, S. (1999). The Proactive Coping Inventory (PCl): A multidimensional research instrument. Paper presented at the 20th International Conference of the Stress and Anxiety Research Society (STAR); 2007 July 12-14, Cracow, Poland. Retrieved September 17, 2007 from http://userpage.fu-berlin.de/health/poland.htm

3. Lerthattasilp T. Burnout among psychiatrists in Thailand:National survey. J Psychiatr Assoc Thailand 2011;56(4):437-448. 